\section{Effective Management of Patients with Amniotic Fluid Embolism in the Intensive Care Unit: Two Case Reports}

\section{Abstract}

Amniotic Fluid Embolism (AFE) is a rare complication of the intra- and early post-partum period, which may also be encountered with cesarean delivery and during abortions. Its symptompatology includes respiratory distress with cyanosis, shock and possibly tonic-clonic seizures. Disseminated intravascular coagulation (DIC) frequently occurs and is usually fatal. The aim of this study is to present the positive outcome and our gained experience from two cases suffering from AFE. Thus, we analyze the case of two patients, in the second trimester of pregnancy, who presented symptoms of AFE. Our paper reveals that in the case of patients with AFE, early diagnosis, prompt management and proper treatment increase survival rate and may ensure complete recovery in a relatively short period of time. However, DIC is a serious aggravating factor, which makes the recovery process slower.

\section{Introduction}

Amniotic fluid embolism was first described in 1911 by Steiner and Lushdaugh and is a catastrophic condition following sudden collapse during labor or in the immediate postpartum period. Even though a rare complication of pregnancy and childbirth, it is usually fatal, with $10 \%$ of maternal deaths that annually occur in the USA to have as a main cause AFE [1].

The clinical picture of AFE is characterized by intense dyspnea, cyanosis, disorders of the central nervous system (CNS) and severe hypotension [2]. The embolism is caused by the entrance of a sufficient quantity of amniotic fluid containing meconium, fetal epithelia,
Leonidas Grigorakos ${ }^{1,2}$, Nikolaos Markou', Daria Lazarescu², Katerina Tzortzopoulou ${ }^{3}$, Magda Gkouni², Eleni Papaioannou², Maria Bikou², Athanasios Moles $^{3}$

1 Assoc. Prof, Faculty of Nursing, National and Kapodistrian University of Athens, Greece.

2 "KAT" Trauma Hospital of Athens, Kifissia, Athens, Greece.

3 "Rea" General Maternity, Athens, Greece.

Contact information:

Leonidas Grigorakos.

Address: 2 Nikis St, 14561, Kifissia, Athens, Greece.

Tel: +30.210 .3709522 .

Fax: +30.210 .3709520 .

” grigorakos@parliament.gr

Keywords

Amniotic Fluid Embolism; Disseminated Intravascular Coagulation; Intensive Care Unit. 
mucin, fluff and other amorphous components into the systemic maternal circulation [3].

The early and accurate diagnosis of AFE and mainly its treatment in the ICU increases the likelihood of cure, despite pessimistic statistics [4].

The aim of this study is to present our gained experience with two cases suffering from AFE in the second trimester of pregnancy.

\section{Case presentation}

\section{Case 1}

The patient was a 38-year-old female with gravida 1, para 1, and abortus 0 . At the age of 18 , she was diagnosed with thyroid disease (without any information on the nature of disease or the therapeutic treatment). She was a former smoker who quit smoking two years before pregnancy. Patient was on the $26^{\text {th }}$ week of a normal pregnancy when suddenly she presented signs of high fever, chills and headache. Due to pregnancy, drugs were not administered but she was monitored. Due to persistence of high fever (which was declining after taking antipyretics), she was admitted to the regional hospital where she was diagnosed with urinary tract infection and was treated with broad spectrum antibiotics and antipyretics. However, on the next day she was transferred to our hospital in order to be closely monitored by her attending physician. The morning of the day she was transferred to our hospital, patient was afebrile and in good condition. At noon of the same day an ultrasound was performed and there were not observed any vital signs of the fetus. Thus, patient underwent artificial labor pains in order to remove the dead fetus that she expelled at evening together with placenta. One hour after, patient developed acidosis, severe dyspnea, cyanosis, bloody sputum and chest pain. She immediately received oxygen and uterine convulsants (ergometrine - $0.4 \mathrm{mg}$ IV q4h) and, because of the severity of the situation, was transferred to the ICU.
Clinically, the patient was confused (Glasgow Coma Scale 13), had gastrointestinal, uterine and nasal bleeding, difficult breathing (48 breaths/min), cyanosis, sinus tachycardia (160 beats/min) and low blood pressure $(70 / 40 \mathrm{mmHg})$. Central venous pressure (CVP) was $16 \mathrm{~cm} \mathrm{H} 2 \mathrm{O}$. On auscultation, she had plenty of nonmusical rhonchi and $A B G s$ with $\mathrm{FiO} 2$ 100\% showed metabolic acidosis: PO2 $51 \mathrm{mmHg}, \mathrm{PCO} 239 \mathrm{mmHg}, \mathrm{pH} 7.13, \mathrm{HCO} 312.3$ $\mathrm{mEq} / \mathrm{L}$. Chest X-ray showed diffuse acinar shadows, occupying both lung fields (Figure 1).

Figure 1: Patient 1. Chest X-ray at ICU admission.

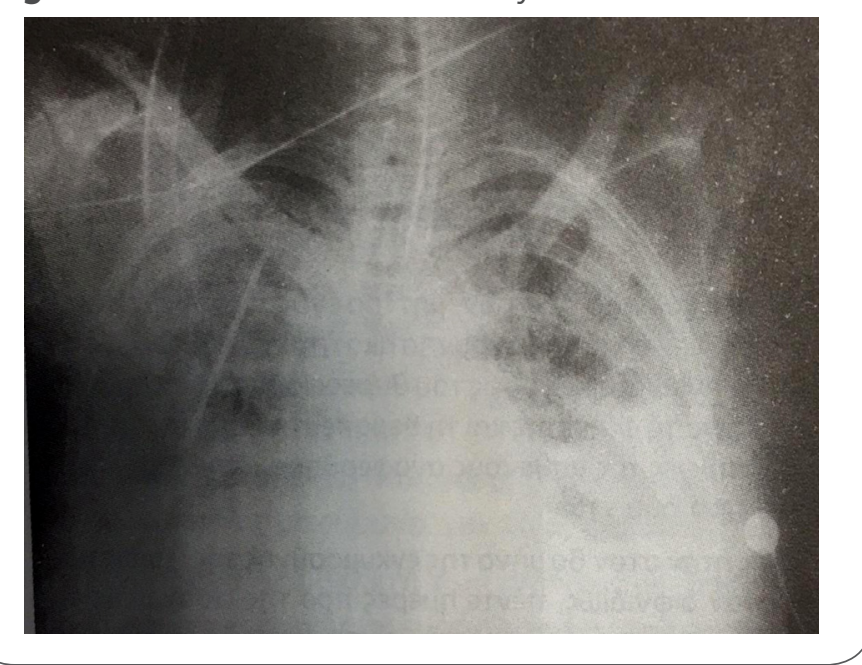

Patient was intubated and placed on mechanical ventilation. With fraction of inspired oxygen ( $\mathrm{FiO} 2$ ) $100 \%$, the arterial blood gases (ABGs) were: $\mathrm{pO} 2$ $70 \mathrm{mmHg}, \mathrm{PCO} 226 \mathrm{mmHg}, \mathrm{pH}$ 7.32, HCO3 13 $\mathrm{mEq} / \mathrm{L}$. Laboratory blood test showed: hematocrit $23.5 \%$, hemoglobin $7.5 \mathrm{mg} \%$, white cells $5000 /$ $\mathrm{mm}^{3}$, platelets $24000 / \mathrm{mm}^{3}$. Prothrombin time was $22 \mathrm{sec}$ (control time $12 \mathrm{sec}$ ), while the partial thromboplastin time was not determined.

Patient's anemia, DIC and hemorrhagic syndrome were treated by administrating 24 units of fresh blood (packed red blood cells), 23 units of fresh plasma and 3 units of platelets. Heparin was administered from the outset, while on ward (30000 IU/24h), because data was supporting the diagnosis of AFE. Haemorrhagic foci were over- 
come with the help of tamponade rear, uterine convulsant drugs administration in intravenous drip infusion (ergometrine - 0.4 mg IV q4h) and continuous lavage with cold saline and administering antacids. Administration of broad spectrum antibiotics (ampicillin - $1 \mathrm{~g}$ IV q6h) and steroids (hydrocortisone - 500 mg IV q6h) was initiated. Inotropic agents were also administered (digoxin $0.5 \mathrm{mg}$ IV push, then $0.25 \mathrm{mg}$ IV q4h for 2 doses, followed by $0.25 \mathrm{mg}$ PO qd), in order to maintain blood pressure.

Patient's condition began to improve substantially after seven days. On the ninth day from ICU admission she was successfully weaned from mechanical ventilation. Hematocrit was then $32 \%$, white cells $8800 / \mathrm{mm}^{3}$ (polymorphonuclear 80\%) and platelets had normal values. Chest X-ray showed important improvement (Figure 2).

Figure 2: Patient 1. Chest $\mathrm{X}$-ray on the day of release from the ICU.

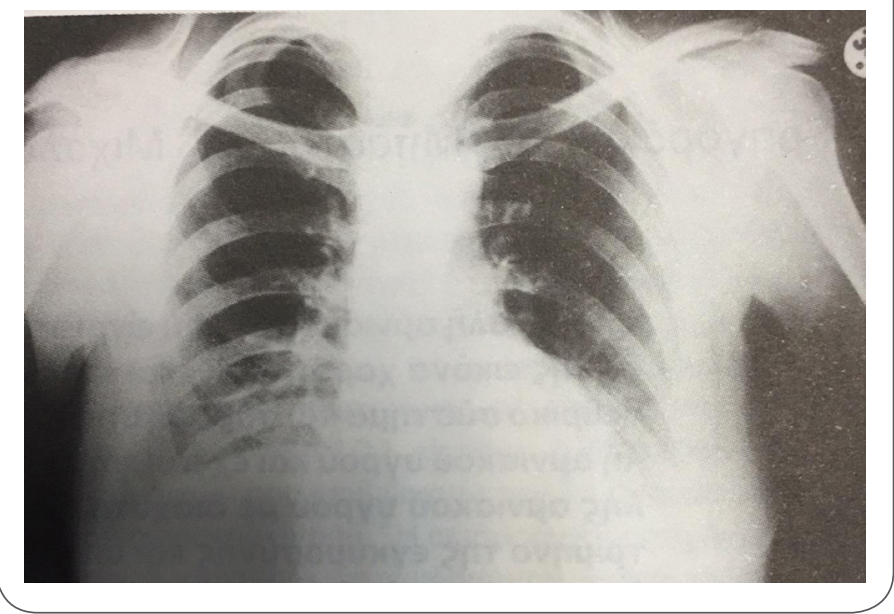

The patient was not bleeding and $A B G s$ with 35\% FiO2 were: PO2 96 mmHg, PCO2 38 mmHg, $\mathrm{pH}$ 7.50. On the $14^{\text {th }}$ day the patient was released from the ICU in good condition.

\section{Case 2}

The patient was a 36-year-old female with gravida 3, para 2, and abortus 1 and living children 0 . She was suffering of Crohn disease and hypothyroidism.
She came to our hospital while she was on the $25^{\text {th }}$ week of gestation and she presented with amniorrhexis.

Due to fetal suffering, an epidural catheter was placed while in the delivery room. She was administered 400mg misoprostol per os and after 4 hours other $400 \mathrm{mg}$ misoprostol vaginally in order to induce labor. Suddenly, the patient became dyspnotic, presented desaturation (SpO2 $89 \%)$, cyanosis, confusion, difficult breathing (49 breaths/min), sinus tachycardia (162 beats/min) and low blood pressure $(60 / 40 \mathrm{mmHg})$. Her CVP was $17 \mathrm{~cm} \mathrm{H} 2 \mathrm{O}$. Patient was directly intubated; fluids were administered, and she was led to the surgery room, where a low cesarean (Pfannenstiel incision) was immediately performed. The newborn was removed and a low Apgar Score at 5 minutes of 4 was recorded.

As her confusion (Glasgow Coma Scale 12) and dyspnea status were worsening, patient underwent computed tomography pulmonary angiography (CTPA) and pulmonary embolism was excluded. Items of actelectasis were observed on the basic bronchopulmonary segments of the lower lobes and in the rear as well as partially in front of the right upper and in the rear of the left-upper-lobe, which are conventional with acute respiratory distress syndrome (ARDS) picture (Figure 3).

The transesophageal echocardiography showed slight left atrial dilatation (45mm), ejection fraction (EF) 74\%, small stenosis and mitral regurgitation probably of rheumatic etiology.

At the time of admission in the ICU, the patient was intubated, put under mechanical ventilation and received intravenous sedation and analgesia. With fraction of inspired oxygen (FiO2) 100\%, the arterial blood gases (ABGs) showed metabolic acidosis with pO2 69 mmHg, PCO2 25 mmHg, pH 7.34 and $\mathrm{HCO} 312 \mathrm{mEq} / \mathrm{L}$.

She was isocoric with (+) light reflex. Within the next hour, she developed sinus tachycardia and hy- 
Vol. 10 No. 257 doi: $10.3823 / 2527$

Figure 3: Patient 2. CTPA 1 hour after intubation.

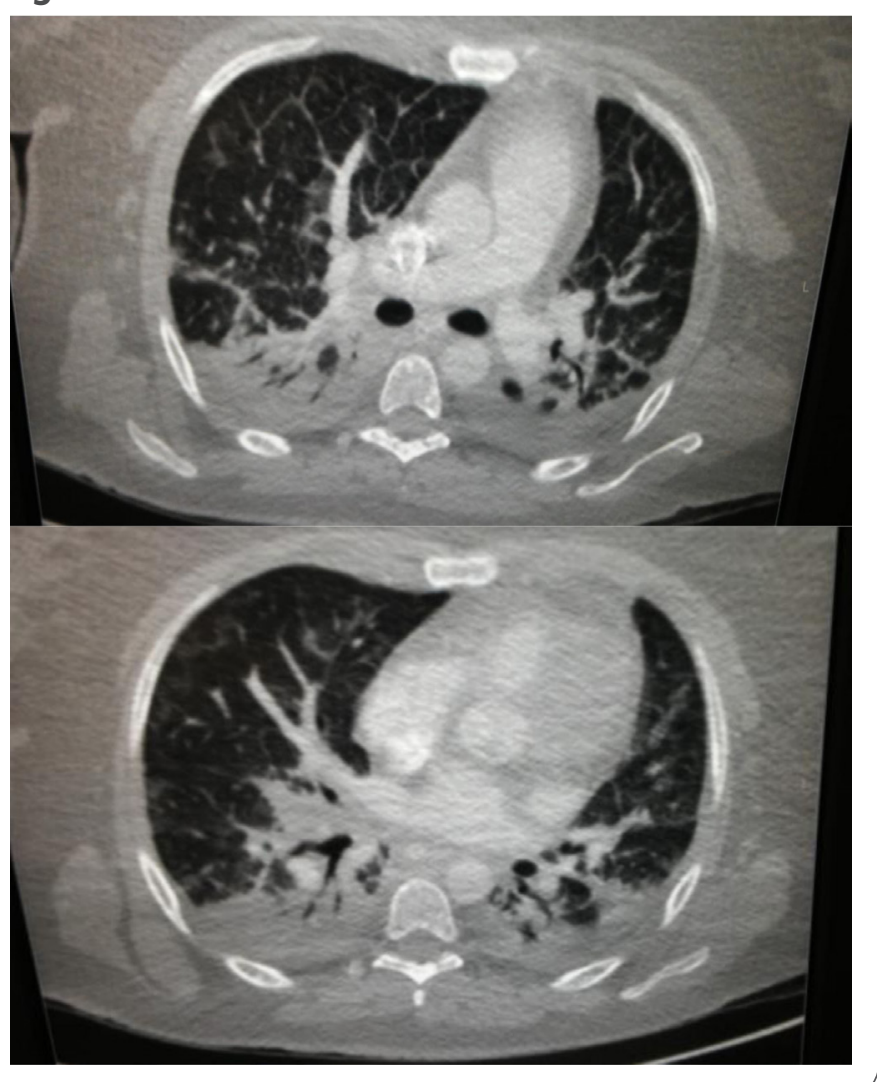

Figure 4: Patient 2. Chest X-ray 1-week after ICU admission.

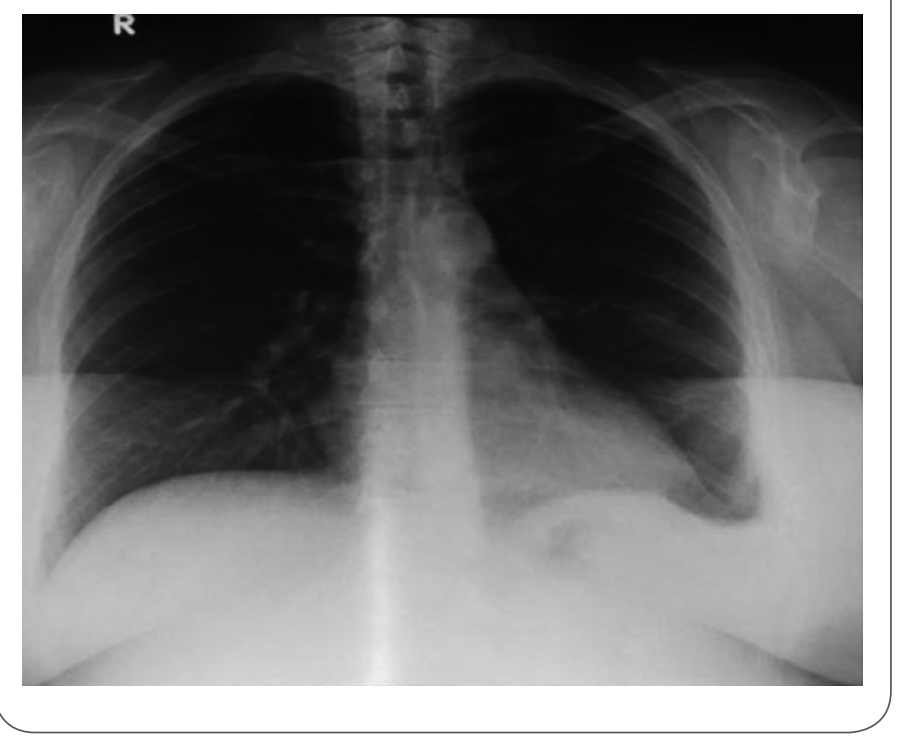

potension, without responding to fluid administration and had to be given norepinephrine $(5 \mu \mathrm{g} / \mathrm{min}$ IV infusion.

At ICU admission her laboratory blood test showed: hematocrit 27\%, hemoglobin $9.6 \mathrm{mg} \%$, white cells $5000 / \mathrm{mm}^{3}$, platelets $21400 / \mathrm{mm}^{3}$. INR: 0.96, PT: 12, Fibrinogen: 460 mg/dl, Urea: 24 mg/ dl, CR: $0.58 \mathrm{mg} / \mathrm{dL}, \mathrm{Na}: 137 \mathrm{mEq} / \mathrm{L}, \mathrm{K}: 4,2 \mathrm{mEq} / \mathrm{L}$, Ca: 8.4 mg/dL, Cl: 109 mg/dL, Mg: 1.6 mg/dL, Total Bil: $1.6 \mathrm{mg} / \mathrm{dL}$, Direct Bil: $1.2 \mathrm{mg} / \mathrm{dL}, \mathrm{Tnl}: 0.18 \mathrm{ng} / \mathrm{L}$, AST: 33 IU/L, ALT: 43 IU/L.

Oxygenation improved quickly. The next morning she was hemodynamically stabilized and did not need more support from vasopressors.

Patient was extubated on day 2 and on day 5 she left the ICU in good condition. The chest X-ray showed a gradual improvement and after one-week patient did not need supplemental oxygen (Figure 4).

\section{Discussion}

Amniotic fluid embolism is a severe condition due to the entrance of amniotic fluid products in pregnant's blood circulation. It may occur during or immediately after childbirth, but can also occur during pregnancy or during curettage [5]. More so, it involves shock, non cardiogenic pulmonary edema, severe respiratory failure and disseminated intravascular coagulation and it usually has fatal outcome [6]. Mortality rate is high, with $50 \%$ of women to die within the first hour from the onset of symptoms.

The incidence of this syndrome is estimated at 1 : 80,000 births and mortality is associated with the $10 \%$ of maternal deaths in the USA [7]. It is also responsible for $12 \%$ of deaths related to legal abortions [8]. The overall mortality from the syndrome amounts to $86 \%$ [1].

In high-risk group are included women with one or more of the following characteristics: (a) multiparous, (b) over the age of 35, (c) labored birth, 
(d) very large fetus, (e) dead fetus (f) meconium in the amniotic fluid, (g) placenta previa, (h) premature separation of the placenta and, finally, (i) a recent or past cesarean. About the latter case, the scar of caesarean section is possibly considered, without confirmation, as an etiologic agent of the syndrome [1]. With regard to the group undergoing abortion, the risk of AFE increases with the age of pregnancy. So, it is zero for pregnancy under 12 weeks, existent in pregnancies between 13 and 15 weeks and greatly increased (24 times greater than the previous group) in pregnancy over 21 weeks [5].

Circulatory failure (shock), which characterizes the entry of amniotic fluid in the pregnant's circulation, may be explained through three pathogenic mechanisms: (a) Pulmonary embolism often involves a large number of pulmonary vessels and results in increased pulmonary resistances. (b) It appears that the amniotic fluid contains vasoactive substances that cause vasoconstriction of pulmonary vessels and worsen pulmonary hypertension. (c) Installed anaphylactic attributed to the meconium content and which is responsible for direct deaths.

The hemodynamic study of patients with AFE, both in terms of diagnosis and monitoring of syndrome's course, is done through a Swan-Ganz catheter. The increased mean pulmonary artery pressure, the elevated Pulmonary Capillary Wedge Region (PCWR) and the low cardiac output are characteristic for embolism with amniotic fluid [9].

In the case of our patients, the only hemodynamic parameter recorded was CVP. However, it has no value for AFE, because, as it is known from experimental data, CVP reaches $70 \%$ of the initial value after intravenous administration of amniotic fluid [10]. Our patients maintained the blood pressure low for too long which ranged, at critical stages, between 60 and $100 \mathrm{mmHg}$. Its increase was obtained only due to inotropic agents that were administered. It is argued that administering digoxin restores several hemodynamic parameters, especiaIly the cardiac output [7].
Respiratory failure in AFE is caused by non-cardiogenic pulmonary edema. The intense hypoxia justifies both cyanosis and manifestations of the CNS, such as anxiety, convulsions and coma. Indeed, the frequency of seizures grand mal type reaches 10$20 \%$ [7].

The bleeding is secondary to DIC and it complicates AFE. The experimental administration of filtered amniotic fluid in the circulation of experimental animals usually did not cause any complication [1]. Rarely, it showed the clinical picture of enriched amniotic fluid particles (containing meconium) [10].

It seems however that the amniotic fluid contains substances that cause the activation of the blood clotting mechanism leading to DIC and profuse bleeding. According to several studies, the amniotic fluid contains a substance of thromboplastine formula ( $1 \mathrm{~mL}$ of tromboplastine is able to clot $10 \mathrm{~L}$ of blood) [1]. Incidence of DIC is reported in $40 \%$ of women who survive during the first hour of AFE [1]. This bleeding is attributed to consumption of fibrinogen, platelets and coagulation factors (mainly of $\mathrm{V}$ and $\mathrm{VIII}$ ) and it is confirmed in vitro with the finding of low fibrinogen values, disorders of prothrombin time, partial thromboplastin time and thrombin time, as well as thrombocytopenia and elevated concentration of fibrin and fibrinogen degradation products.

In our case, only patient 1 fully developed the DIC syndrome with all confirmatory laboratory findings and cause, which in this case was the amniotic fluid entry into the maternal circulation.

In clinical practice, the diagnosis of the syndrome is based on (a) the combination of the historical of pregnancy or childbirth with potential increased risk factors, (b) patient's clinical picture with dyspnea, cyanosis, bloody sputum, severe hypotension or shock and, if the patient survives, intense bleeding during the first 24-hours and (c) radiological and hematological findings consistent with non-cardiogenic pulmonary edema and DIC, respectively. 
AFE is fully diagnosed postmortem, through findings of embryonic wastage in the pulmonary vascular bed (meconium, epithelia, mucus and sebum). However, the rapid antemortem diagnosis would be very helpful in confirming the syndrome and in the early initiation of intensive care.

The search of embryonic blood residues usually fails as they are rapidly removed from circulation through embolism in the pulmonary vessels. Consequently, collection of $10 \mathrm{~mL}$ of blood from the pulmonary artery through the catheter Swan-Ganz is usually the method used to find embryonic products in the maternal blood. This method includes the blood centrifugation for $10 \mathrm{~min}$ at 2000 RPM, washing the precipitate with saline, coating and the use of specific stains. The findings are usually positive until the third day of the invasion of the syndrome [11]. We did not have the relevant experience of death and so the diagnosis was based on standard combination of clinical and laboratory findings.

The usual treatment of respiratory failure in these patients includes mechanical ventilation, positive end-expiratory pressure (PEEP) and diuretics, while limiting fluid volume administered. In our case, mechanical ventilation was applied for 8 (patient 1) and 2 (patient 2) days, without PEEP, as under mechanical ventilation, patients' oxygenation was satisfactory with a low concentration of O2. Possibly, an important role in the relatively good response of the respiratory system played either the amount of embolized amniotic fluid or the early recognition of the syndrome and the rapid onset of heparin therapy.

The treatment of DIC and resulting bleeding involves addressing the operative cause (usually the fetus is removed), the administration of fresh plasma, platelets (if their value in the blood is below $50000 / \mathrm{mm} 3$ ) and fibrinogen or cryoprecipitate rich in fibrinogen where the value in serum is less than $100 \mathrm{mg} \%$ [12].

In the case of our patients, the treatment was in line with the above guidelines, without allocation of fibrinogen but with an additional administration of packed red blood cells because of the extremely low hematocrit. Although there is disagreement about its usefulness, heparin was also administered (patient 1) [10, 13]. However, in cases of DIC under AFE, without positive course, as in our case, its administration is imposed [12].

\section{Conclusion}

In conclusion, it is considered that the rapid recognition of the syndrome, taking into consideration high-risk groups and the early diagnosis, as well as effective management and treatment in the ICU, may improve the survival rates of patients with AFE, while ensuring complete recovery in a relatively short period of time. Nonetheless, DIC is a serious aggravating factor, which makes the recovery process slower.

\section{Abbreviations}

AFE: Amniotic Fluid Embolism; DIC: Disseminated Intravascular Coagulation; ICU: Intensive Care Unit; ABGs: Arterial Blood Gases; CTPA: Computed Tomography Pulmonary Angiography; ARDS: Acute Respiratory Distress Syndrome; PEEP: Positive EndExpiratory pressure; PCWR: Pulmonary Capillary Wedge Region.

\section{Competing Interest}

The authors declare that there is no conflict of interest regarding the publication of this paper.

\section{Financial support \\ No}

\section{Acknowledgments}

No acknowledgments to report. 


\section{References}

1. Conde-Agudelo A., Romero R. Amniotic fluid embolism: An evidence-based review. Am J Obstet Gynecol., 2009, 201(5), 445.e1-445.13. doi: 10.1016/j.ajog.2009.04.052.

2. Lewis, G., editor. The seventh report on confidential enquiries into maternal deaths in the United Kingdom. London: $\mathrm{CEMACH}$; 2007. The confidential enquiry into maternal and child health (CEMACH). Saving mother's lives: reviewing maternal deaths to make motherhood safer -2002-2005.

3. Thomson AJ, Greer IA. Non-haemorrhagic obstetric shock. Baillieres Best Pract Res Clin Obstet Gynaecol., 2000, 14, 19-41.

4. Berg CJ, Callaghan WM, Syverson C, Henderson Z. Pregnancyrelated mortality in the United States, 1998 to 2005. Obstet Gynecol, 2010, 116,1302.

5. Abenhaim HA, Azoulay L, Kramer MS, Leduc L. Incidence and risk factors of amniotic fluid embolisms: a population-based study on 3 million births in the United States. Am J Obstet Gynecol., 2008, 199,49.e1-8.

6. Rath WH, Hofer S, Sinicina I. Amniotic Fluid Embolism: an Interdisciplinary Challenge Epidemiology, Diagnosis and Treatment. Dtsch Arzteb/ Int, 2014 Feb; 111(8): 126-132.

7. Patra AP, Shaha KK, Rayamane AP. Review of 24 cases of Maternal Deaths from Amniotic-Fluid Embolism: in Correlation with Clinical and Histopathological Findings. Sch. Acad. J. Biosci., 2013, 1(3),85-89.

8. Lichtenberg ES and Grimes DA. Surgical Complications: Prevention and Management, in Management of Unintended and Abnormal Pregnancy: Comprehensive Abortion Care (eds M. Paul, E. S. Lichtenberg, L. Borgatta, D. A. Grimes, P. G. Stubblefield and M. D. Creinin), 2009. Blackwell Publishing Ltd., Oxford, UK. doi: 10.1002/9781444313031.ch15
9. Dean L, Rogers R, Harley R, Hood D. Case Scenario: Amniotic Fluid Embolism. Anesthesiology, 2012, 116, 186-192. doi: 10.1097/ALN.0b013e31823d2d99

10. Clark SI. Amniotic fluid embolism. Clin Perinatol, 1986, 13,801811.

11. Kaur K, Bhardwaj $M$, Kumar $P$, Singhal $S$, Singh $T$, Hooda $S$. Amniotic fluid embolism. J Anaesthesiol Clin Pharmacol., 2016, 32(2), 153-159. doi: 10.4103/0970-9185.173356.

12. Wada H, Matsumoto T, Yamashita Y. Diagnosis and treatment of disseminated intravascular coagulation (DIC) according to four DIC guidelines. Journal of Intensive Care, 2014, 2,15. DOI: 10.1186/2052-0492-2-15.

13. Strickland MA, Bates GW, Whitworth NS, Martin JN. Amniotic Fluid Embolism: Prophylaxis With Heparin and Aspirin. South. Med. J., 1985, 78 (4), 377-379.
Publish in International Archives of Medicine

International Archives of Medicine is an open access journal publishing articles encompassing all aspects of medical science and clinical practice. IAM is considered a megajournal with independent sections on all areas of medicine. IAM is a really international journal with authors and board members from all around the world. The journal is widely indexed and classified Q2 in category Medicine. 